\title{
Tuberculosis - Still a major health problem
}

\author{
EARL S HERSHFIELD, MD, FRCPC
}

$\mathrm{T}$ UBERCULOSIS REMAINS A MAJOR HEALTH PROBLEM worldwide, with at least three million deaths annually (1). Each year there are nearly 10 million new cases, of which four to five million are smear positive and, thus, highly contagious. The problem is smallest in the developed countries of Europe, North America, Australia and New Zealand. The largest problem exists in southeast Asia and subSaharan Africa. In Latin America, where the incidence is generally lower than in Africa, it is still five to 30 times higher than in Canada. Tuberculosis is primarily a socioeconomic problem associated with overcrowding, poor hygiene, lack of fresh water and limited access to health care. The lack of a well organized health care infrastructure for case finding and treatment of tuberculosis complicates disease control in these countries. In the developing countries, many cases are unrecognized, incorrectly diagnosed or unreported, and the available statistical data significantly underestimate the problem of tuberculosis in the world. In these countries only cases that are sputum smear positive are diagnosed, as facilities for culture are almost nonexistent. Tuberculosis in children is rarely diagnosed unless a complication occurs. Extrapulmonary tuberculosis is not often recognized.

The rates of tuberculosis in Canada have continued to fall steadily since the early 1970s. However, in 1989, for the first time in 25 years, the actual number of cases as well as the rates of tuberculosis rose (Table 1) (personal communication). The rise in cases occurred in two provinces and in the Northwest Territories. In Ontario, the rise was attributed to an increase in the number of cases in the foreign-born, especially those who have been in Canada for 10 years or less; in Saskatchewan the rise was attributed to an increased number of cases in the aboriginal popula- tion; and an increase in the number of cases in the Northwest Territories was due to an outbreak in an isolated community which has now been brought under control. Preliminary figures for 1990 show that the rise in total cases in Canada will continue. Although not yet a major problem in Canada, concomitant tuberculosis and human immunodeficiency virus infection remains a potential source of new cases of tuberculosis.

The problem that tuberculosis presents for physicians in Canada is illustrated in two reports appearing in this issue of The Canadian Journal of Infectious Diseases.

Drs Mah and Fanning report an epidemic in a closed aboriginal community in Alberta. In the second article, Drs Navas and Wang review one of the serious complications of tuberculosis, meningitis. The report from Alberta illustrates the need for constant vigilance in the aboriginal population, since rates per 100,000 population in Canada in the aboriginal peoples remain 10 times higher than rates in nonaboriginal Canadians. Since the aboriginal population is heavily infected with the tubercle bacillus, the chance of an adult developing active infectious tuberculosis remains high throughout his or her lifetime. Because of the poor socioeconomic conditions that exist in many aboriginal communities, spread within such communities becomes a real and dangerous possibility. As the authors stress, BCG vaccination may be helpful in reducing the number of individuals who will be infected, and will eliminate almost entirely the development of meningitis and disseminated disease. However, case finding, case holding, compliance with the treatment regimen, and preventive therapy for those infected but not yet diseased, must remain the mainstays of any tuberculosis control program. The diagnosis of tuberculosis is easy, and the treatment well 
TABLE 1

Trends in tuberculosis notification rates in Canada, the provinces and Northwest Territories, $1979-89$

\begin{tabular}{|c|c|c|c|c|c|c|c|c|c|c|c|c|c|}
\hline Year & Canada & Nfld & PEI & NS & NB & Que & Ont & Man & Sask & Alta & $B C$ & Yukon & NWT \\
\hline 1978 & 2940 & 115 & 2 & 76 & 78 & 836 & 815 & 176 & 148 & 240 & 403 & 6 & 45 \\
\hline 1979 & 2760 & 75 & 5 & 79 & 79 & 797 & 770 & 177 & 121 & 225 & 377 & 12 & 43 \\
\hline 1980 & 2761 & 89 & 7 & 83 & 59 & 808 & 764 & 172 & 137 & 241 & 371 & 2 & 28 \\
\hline 1981 & 2529 & 79 & 8 & 83 & 72 & 651 & 742 & 151 & 122 & 216 & 370 & 8 & 27 \\
\hline 1982 & 2472 & 72 & 2 & 59 & 42 & 649 & 730 & 154 & 110 & 203 & 414 & 3 & 34 \\
\hline 1983 & 2356 & 63 & 4 & 35 & 58 & 618 & 662 & 208 & 118 & 189 & 363 & 6 & 32 \\
\hline 1986 & 2145 & 56 & 3 & 36 & 20 & 503 & 657 & 136 & 152 & 209 & 346 & 4 & 23 \\
\hline 1987 & $1972 r$ & 34 & 1 & 30 & 24 & $432 r$ & 645 & 126 & 156 & 205 & 298 & 1 & 20 \\
\hline 1988 & 1947 & 65 & 4 & 26 & 18 & 423 & 635 & 111 & 149 & 176 & 300 & 4 & 36 \\
\hline 1989 & 2035 & 42 & 5 & 30 & 29 & 420 & 711 & 100 & 216 & 133 & 288 & 5 & 56 \\
\hline \multicolumn{14}{|c|}{ Rates per 100,000 population } \\
\hline 1983 & 9.5 & 10.9 & 3.2 & 4.1 & 8.2 & 9.5 & 7.5 & 19.9 & 11.9 & 8.0 & 12.8 & 26.9 & 66.1 \\
\hline 1984 & 9.4 & 9.8 & 3.2 & 4.9 & 5.5 & 9.0 & 7.7 & 17.2 & 11.4 & 9.4 & 13.8 & 22.9 & 40.5 \\
\hline 1985 & 8.5 & 5.9 & 0.8 & 3.5 & 5.3 & 8.9 & 7.1 & 13.5 & 14.2 & 7.6 & 11.5 & 4.4 & 17.7 \\
\hline 1986 & 8.4 & 9.7 & 2.3 & 4.1 & 2.8 & 7.6 & 7.2 & 12.6 & 14.9 & 8.7 & 11.9 & 17.9 & 44.7 \\
\hline $1987 r$ & $7.7 r$ & 6.0 & 0.8 & 3.4 & 3.4 & $6.6 r$ & 7.0 & 11.7 & 15.4 & 8.6 & 10.2 & 4.1 & 38.7 \\
\hline 1988 & 7.5 & 11.4 & 3.1 & 2.9 & 2.5 & 6.4 & 6.7 & 10.2 & 14.7 & 7.3 & 10.1 & 15.8 & 68.8 \\
\hline 1989 & 7.8 & 7.4 & 3.8 & 3.4 & 4.0 & 6.3 & 7.4 & 9.2 & 21.4 & 5.5 & 9.4 & 19.7 & 104.9 \\
\hline
\end{tabular}

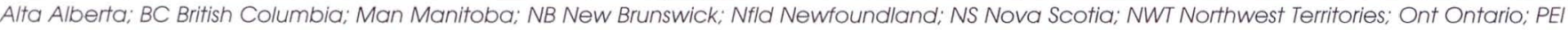
Prince Edward Island; r Revised figures; Que Quebec; Sask Saskatchewan. (Reprinted with the permission of Statistics Canada)

known, but patient adherence to treatment regimens is well below acceptable levels. Thus the introduction of directly observed treatment regimens which will quickly identify noncompliers is an essential new element in the elimination of the disease in Canada.

The report by Navas and Wang illustrates that tuberculous meningitis must be part of the differential diagnosis of patients with neurological problems. Their paper illustrates very clearly that tuberculous meningitis occurs in the immigrant population - especially in families coming from countries with high tuberculous disease and infection rates. Special efforts need to be instituted so that adequate follow-up of suspicious cases in specific immigrant groups is carried out.

Of the tuberculosis cases reported in Canada between 1979 and 1981: foreign-born individuals made up 35\% of the total; cases in the aboriginal population made up 15\%; and 50\% occurred in other Canadians. By 1987-89, these percentages had shifted so that the foreign-born made up $48 \%$ of the total, aboriginals $19 \%$ and other Canadians $33 \%$.
Cases of inactive tuberculosis identified in the immigration process need to be followed in Canada. The regulations clearly state that all patients with a diagnosis of inactive tuberculosis shall be placed on surveillance as part of immigration requirements. In practice, there is often a long delay between the arrival of such individuals in Canada and notification to the province of final destination. The eventual medical examination is done in that province or territory (2).

The two articles in the present issue will hopefully focus the attention of practising physicians on the problem of tuberculosis, an exotic disease in the minds of some, but a practical problem to all practising physicians.

\section{REFERENCES}

1. Styblo K, Rouillon A. Tuberculosis in the world. II. Estimated global incidence of smear-positive pulmonary tuberculosis. Unreliability of officially reported figures on tuberculosis. Bull Int Union Tuberc Lung Dis 1981;56:118-26.

2. Orr PH, Manfreda J, Hershfield ES. Tuberculosis surveillance in immigrants to Manitoba. Can Med Assoc J 1990; 142:453-8. 


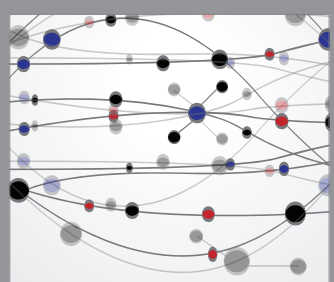

The Scientific World Journal
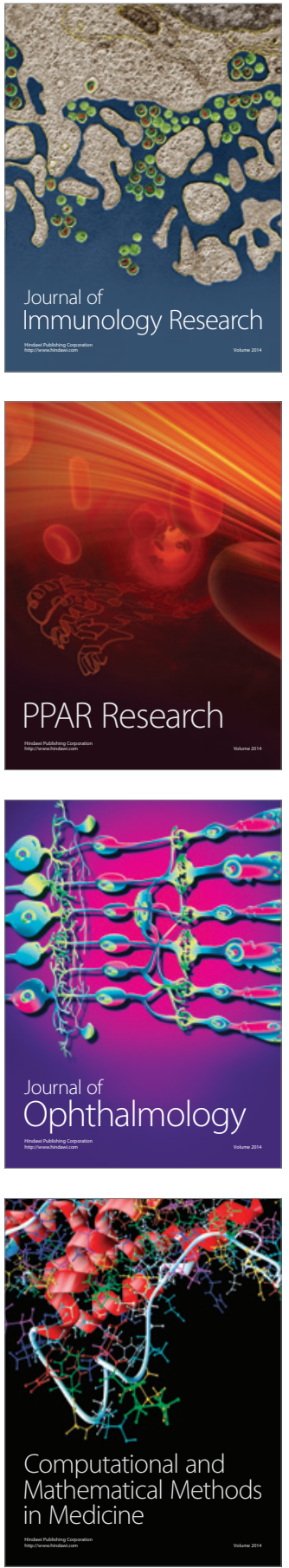

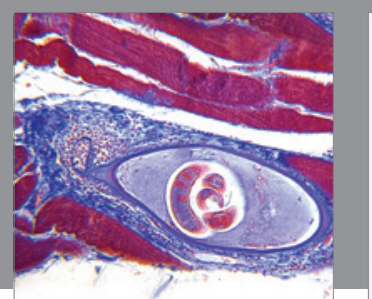

Gastroenterology Research and Practice

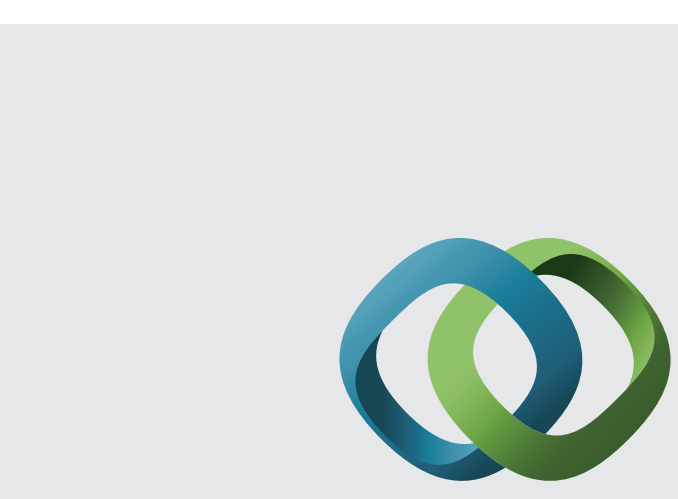

\section{Hindawi}

Submit your manuscripts at

http://www.hindawi.com
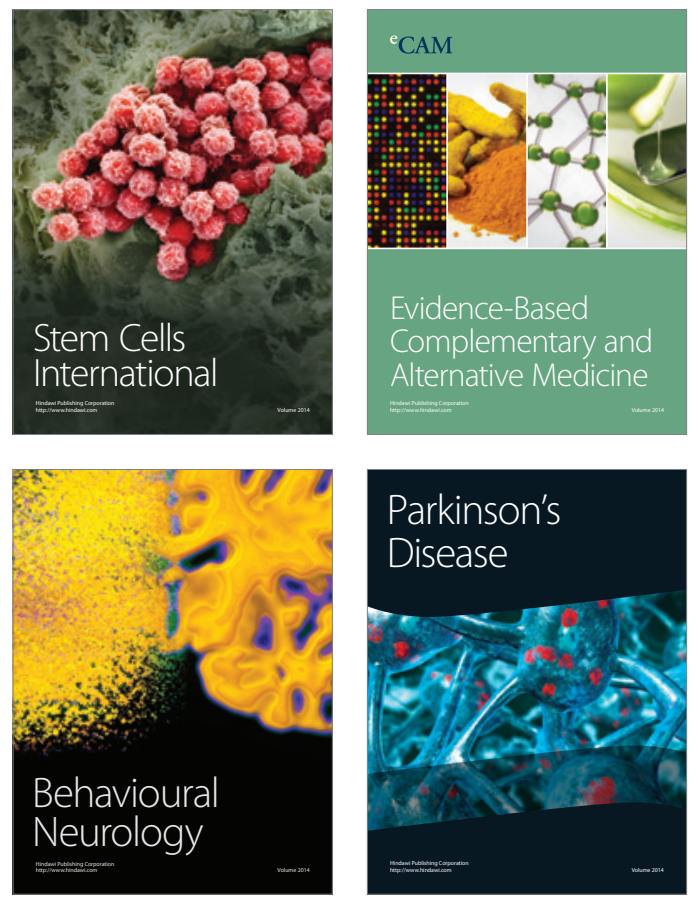
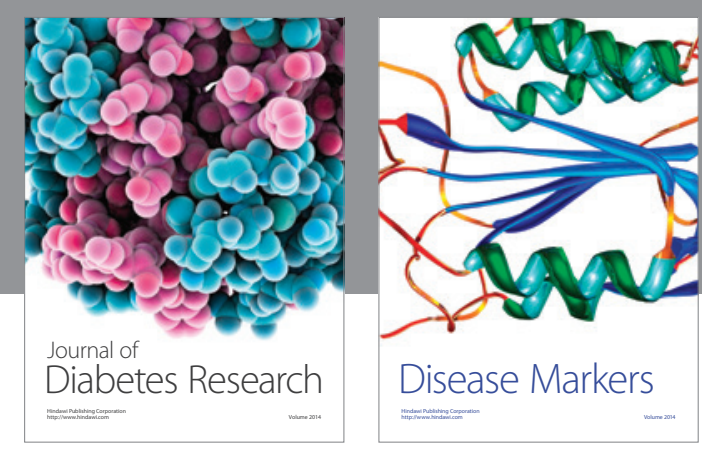

Disease Markers
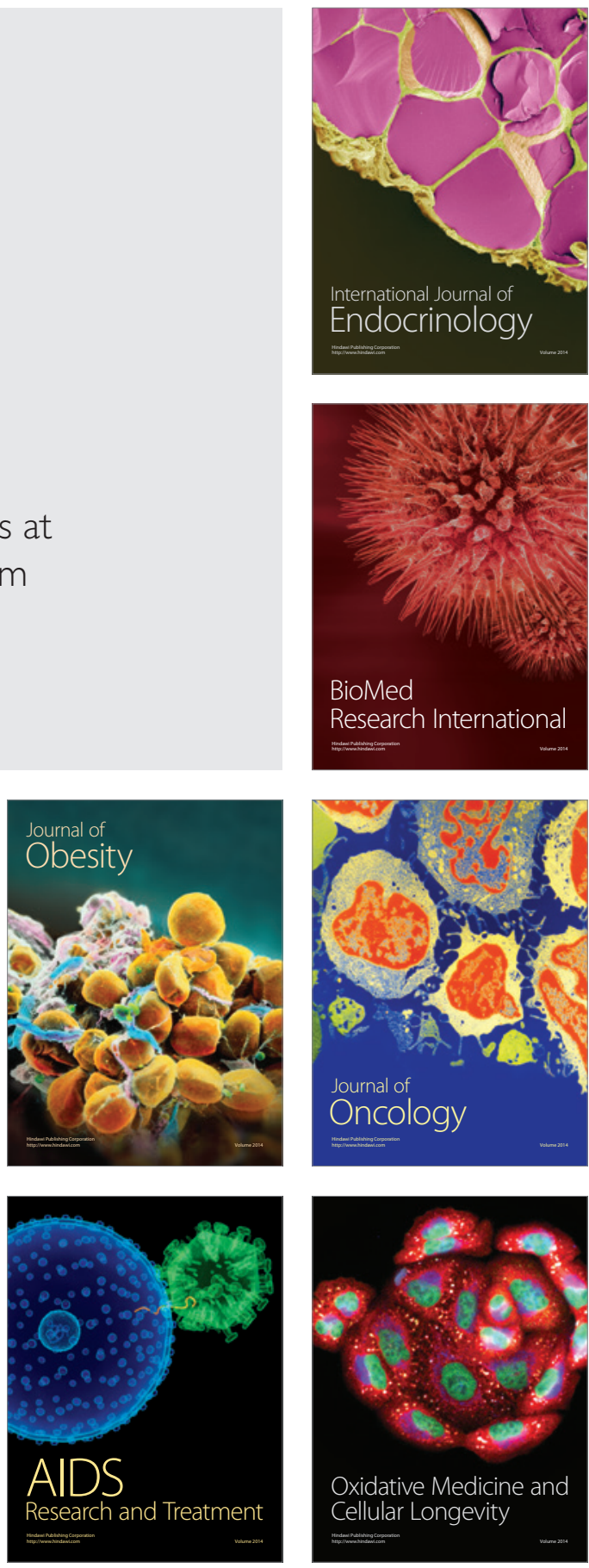